\title{
Ethics and the Foundation of Global Justice Amartya Sen*
}

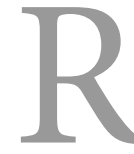

everend Dr. Martin Luther King, Jr., wrote in his Letter from Birmingham Jail: "Injustice anywhere is a threat to justice everywhere." for his agitation to end injustice against non-white people in his own country, and he would be killed soon after by an assassin who hated him and his vision.

King's active political work was largely confined to the United States and was mainly concerned with injustices from which African-Americans particularly suffer. But his ethical and political reflections were not confined only to issues of local injustice. As a visionary leader, King looked at the huge injustices across the globe, and he discussed why people everywhere had reason to want to help others suffering from injustice, deprivation, and discrimination-no matter where they lived in the world.

The connection between local justice in one's own country and global justice in the world is important to understand for an adequate appreciation of the intellectual discipline of thinking about justice. Even though actual agitations for justice may be conducted locally, the ethical basis of the demands for justice must have some universal relevance. Underlying King's social thinking is a global understanding that, I would argue, is central to the conception of justice. We cannot have an adequate conceptual grip on fighting injustice if we confine our attention only to what we see locally, ignoring what happens in the rest of the world.

And yet the dominant theories of justice in contemporary political philosophy typically have a narrowly national character, and they have tended to be defined only for a collectivity of people ruled by a sovereign state, with a state-based

\footnotetext{
${ }^{\star}$ This essay is based on a talk given at the University of Utah on April 22, 2016, at an event sponsored by the Daniels Fund Ethics Initiative at the Eccles School of Business. I have greatly benefited from discussions with Akeel Bilgrami, Deen Chatterjee, Erin Kelly, Lionel McPherson, Thomas Nagel, Hilary Putnam, and John Rawls.
} 
institutional structure. This applies even to the most influential-and in many ways the most powerful-theory of justice in modern political thought, John Rawls's theory of "justice as fairness." There is certainly a great deal to learn from these theories. Rawls's work in particular has radically enhanced the subject of political philosophy of justice. We do not have to be dismissive of the importance of these theories (indeed far from it) even if we were to argue, as I presently will, that they are at least partly_but rather seriously_mistaken.

I begin by examining an influential critique of the coherence of the idea of global justice that has had a huge effect in inhibiting ethical as well as economic discussion of justice across the world. Skepticism about the idea of global justice in the contemporary world can be found in the writings of many authors, including John Rawls, but it is Thomas Nagel, another leading philosopher of our time, who has articulated the grounds for that skepticism most clearly.

Nagel has argued that the pursuit of justice demands the presence of a sovereign state, which is needed for establishing the institutional structure that a just social order would require. Since there is no global state in our world, the idea of global justice, it is argued, cannot be but a fantasy. As seen in this perspective, there is an absolute necessity of a sovereign state for a viable theory of justice. Nagel attributes this recognition to the writings of Thomas Hobbes in the seventeenth century. ${ }^{2}$ Modern political theorists who likewise situate their analysis of justice within the orbit of a sovereign state-including Rawls, Ronald Dworkin, and others ${ }^{3}$ have found it, as Nagel has put it, "very difficult to resist Hobbes's claim about the relation between justice and sovereignty." And he goes on to say that "if Hobbes is right, the idea of global justice without a world government is a chimera." 4

Is the pursuit of global justice really a fantasy? Was Hobbes right, as characterized here, to dismiss the quest for justice without a sovereign state? And going further, was that really Hobbes's claim? I would argue that theories of state originating in seventeenth- and eighteenth-century Europe, including those of Hobbes (and others pursued by John Locke and Jean-Jacques Rousseau), were primarily addressed to finding a good basis for a state (including good reasons for having a state at all), and they cannot be seen as attempts to define the limits of the idea of justice. ${ }^{5}$ The establishment of a Hobbesian state-a Leviathan-is clearly motivated by its ability to facilitate the pursuit of justice, but that does 
not entail that the very idea of justice must be confined within the narrow box of what can be pursued through a sovereign state. Indeed, some concept of justice is needed prior to examining the ways and means of advancing justice-in this case through the establishment of a sovereign state. ${ }^{6}$

There is a similarity here with the use of the prior idea of the "inalienable rights" of human beings in the American Declaration of Independence in 1776 to motivate the making of a national constitution. Something similar can be said about the French declaration, in 1789, of "the rights of man," which influenced the search for an appropriate constitution for post-revolution France. There is clearly a role for the foundational idea of the rights of human beings in motivating the search for constitutions and legislation, but this connection does not make the idea of foundational rights itself parasitic on the constitution enacted. The powerful role of the state, as discussed by Hobbes, in ameliorating such adversities as the "nasty, brutish, and short" lives of people can be, similarly, a fine beginning for a theory of the state, which draws on the basic connection between the idea of justice and the need to remove these adversities. But there has to be some idea of justice before airing the claim that a state would help us to pursue it.

In fact, we cannot adequately understand what Richard Tuck calls "Hobbes as a modern natural law theorist" and "Hobbes as a moralist" if we try to confine Hobbes's understanding of justice as emerging only after a sovereign state is established.7 Such foundational ideas as the value of "self-preservation"-important to Hobbes as it also was to Grotius-precede, rather than follow, the establishment of a Hobbesian state. If there is some difficulty in talking about what would be needed for enhancing global justice-or reducing global injustice-it can hardly arise from the nonexistence of a global sovereign state (even though it may be very plausible to think that the pursuit of justice could be greatly helped if such a sovereign state existed).

We can ask how the idea of justice in general, and that of global justice in particular, relate to the discipline of ethics, and what we can say about the ethical foundations of the idea of global justice. ${ }^{8}$ Even though I have had occasion to express some disagreements with John Rawls (and I shall have to come back to those disagreements before long), I draw now on an insightful and far-reaching analysis presented by him on the connection between ethics and the demands of 
impartiality. The need for an ethical judgment to be impartial for its viability has been discussed for a long time. William Shakespeare ridiculed the allegedly ethical conclusions people try to draw that are biased toward the promotion of their own advantages. In King John, Shakespeare portrays Philip the Bastard caricaturing the nature of reasoning based on self-interest:

Well, whiles I am a beggar, I will rail

And say that there is no sin but to be rich;

And being rich, my virtue then shall be

To say that there is no vice but beggary.

In developing his theory of justice, John Rawls has made powerful use of the need for objectivity through impartiality, in a way that one's own interests do not bias what one argues for. For example, Rawls invokes the idea of choosing principles of justice in a hypothetical "original position," in which people do not know what their own vested interests and specific perspectives are. The "veil of ignorance" helps to incorporate impartiality as a crucial building block of Rawls's theory of justice as fairness. Rawls's analysis of justice as fairness has credibility and appeal that are closely linked with the foundational demands of impartiality. Furthermore, Rawls has argued powerfully that the objectivity of an ethical or political claim, for example about justice and injustice, must be linked with its survival in open public reasoning. As Rawls puts it, for a political conviction to be objective, it has to be shown that "there are reasons, specified by a reasonable and mutually recognizable political conception (satisfying those essentials), sufficient to convince all reasonable persons that it is reasonable." ${ }^{\prime \prime}$ We have to look for, in Rawls's words, "a public framework of thought" that provides "an account of agreement in judgment among reasonable agents."

Note that this way of assessing a political judgment invokes the discipline of public reasoning, but does not invoke a sovereign state. If other people, willing and able to use reason and trying hard to make sense of a claim, cannot see any justification for it, then that would contribute to undermining the claim. I do not enter here into the question whether the agreement to emerge in public reasoning must reflect a cognitive recognition of the truth of the claim, or whether the impartial agreement can reflect some other feature of the discipline of reasoning. The Rawlsian approach is compatible with more than one way of interpreting the test of public reasoning, and I abstain here from going into the important meta-ethical issues that relate to the use of the discipline. ${ }^{10}$ 
Starting off from Rawls, but departing from him in some significant ways, I have tried to explore the idea of justice in a book called The Idea of Justice, which draws on giving a central place to impartiality, but differs from Rawls's approach in several distinct respects, to be discussed presently. ${ }^{11}$ The idea of justice, thus constructed, can inter alia accommodate many concerns about the scope and feasibility of global justice. ${ }^{12}$

First, the demands of public reasoning need not be confined to people within a nation, as it is, in effect, in standard theories of justice, including Rawls's justice as fairness. Public reasoning can go across borders in many cases (as it did in questioning the justice of the intervention in Iraq by an American-led coalition in 2003, or in attributing injustice to the inaction of the global community in dealing with particular pandemics in Africa). Those who take a severely isolated view of different cultures (or of "different civilizations") may be skeptical of the possibility of such international discussion, but it can be argued that this would be a peculiarly limited view of the ability of human beings to listen, understand, and reason. Indeed, I would propose that such a limiting view would be needlessly pessimistic about intercountry dialogue, while being unrealistically optimistic of our ability to understand each other perfectly well within a given country (which can include many divergent traditions of political, social, economic, and scientific thinking).

Second, while the dominant theories of justice concentrate on identifying perfectly just societies-or ideal social institutions-the use of theories of justice for global as well as national judgments mainly lie in being able to compare social alternatives, none of which may have the superlative quality of being ideal or perfect. When slavery was abolished on the basis of compelling arguments and hardfought battles, abolitionists did not have to claim that the removal of slavery would make the world perfect, and they did not, in fact, even have to agree on what a perfectly just society would look like. The issue involved a comparative judgment: whether the abolition of slavery would make the world radically less unjust; it was not the attribution to a slaveless society of superlative excellence that could not be transcended.

Third, even comparative exercises may not yield complete agreements, so that the basic relation of evaluative gradation may be that of a partial order, rather than a complete ordering. ${ }^{13}$ For example, people who agreed on the immediate necessity of abolishing slavery could well have disagreed on many other comparisons of social institutions, such as the relative roles to be given to public and private enterprises in dealing with governance or commerce. 
Fourth, unlike in the Rawlsian theory of justice as fairness, the domain of the discourse on justice must not be confined only to the choice of institutions, but must include other factors, such as behavior patterns, which can importantly influence the social states that emerge. Rawls assumes that once just institutions have been chosen, everyone would behave appropriately for the success of those institutions. That is an inspiring thought, but the grand assumption of behavioral correctness leaves out many of the more difficult problems in the pursuit of justice, which had, as it happens, received penetrating attention already in the eighteenth century from David Hume, Adam Smith, and the Marquis de Condorcet, among others. No theory of justice for practical use-whether within a nation or across borders-can sensibly ignore such problems as greed, corruption, and cupidity, and must, therefore, include more than the choice of social institutions-with the assumption of perfect behavior from all.

The ethics of justice can hardly abstain from the basic economics of behavioral motivation. Even Hobbes's reasoning about the "social contract" for the pursuit of justice included behavioral as well as institutional concerns. While institutions can be devised in a way that helps what in contemporary game theory is called "incentive compatibility" (Hobbes's reasoning was an early example of addressing that question, among others), the role of behavioral variability cannot be fully eliminated through institutional choice alone. If public discussion on people's responsibility to each other-because of economic, social, or environmental interdependence-is taken to be important for the pursuit of justice, it is at least partly based on the hope that such discussion can influence people's actual behavior, which cannot be made into a redundant concern in any practical theory of justice.

Even though I have argued that it would be a mistake to attribute to Hobbes the belief that justice cannot be viably discussed except within the framework of a social contract, there is little doubt that Hobbes did put much emphasis on the role of a properly devised social contract in helping the pursuit of justice, including helping people to promote their self-preservation and, in particular, making the lives of people less nasty, less brutish, less short, and less isolated. Hobbes's important role in the emergence of social contract theory can hardly be denied, and yet it is possible to argue that the dependence of the idea of justice on the devise of a social contract has become, as was discussed earlier, much more 
all-encompassing in contemporary political philosophy than it was in Hobbes's own writing.

The social contract approach has perhaps been the strongest influence on the analysis of justice in European thought from the eighteenth century to our own time. In this reasoning, an assumption is made about a contract that the members of the society might have arrived at without being biased toward their own interests and circumstances. As was discussed earlier, John Rawls, in particular, has strongly argued for judging justice on the basis of principles that would have been chosen in a state of primordial equality ("the original position"), when no one quite knows who he or she is going to be. It is the fairness of the principles of justice chosen in the original position that makes those principles the appropriate criteria for justice in the actual world, in the theory of justice as fairness, powerfully advocated by Rawls and his many followers.

There can, however, be serious doubts about whether we can reasonably assume that in the Rawlsian original position there would, in fact, be a complete agreement on the exact demands of perfect justice, even among reasonable people thinking on this question in an impartial way. There can be very substantial differences on, say, how much priority to give to personal liberty over competing concerns of social equity or economic deprivation (an issue that Herbert Hart has done much to emphasize). ${ }^{14}$ Contrasts between different perspectives need not disappear even when different persons are all being impartial. Differences between distinct persons' evaluative assessments do not arise only from their vested interests and personal concerns, but can reflect different priorities and points of concentration-each considered in an impartial way. Since the institutional structure to be chosen for the society based on a social contract depends on such an agreement, there remains a major lacuna in the strategy on which at least some versions of the social contract approach-like Rawls's-rely.

There are other problems as well. Among these, there is the difficulty that arises from the fact that the specification of ideally just institutions does not, on its own, tell us much about how to rank departures from these ideal arrangements. Since the world in which we live, and are most likely to live in the foreseeable future, departs from the vision of ideal justice, it is critically important to have guidance on how we can rank differently imperfect societies. To say that the closer we are to the perfectly just world, the better it would be in terms of justice is not very helpful since (1) we may not be able to agree on a perfectly ideal world, and (2) even if we could, there are different ways of getting closer to an ideal world in multidimensional 
comparison. We have to ask such questions as whether it is more important to pursue personal liberty or economic or social equity, and whether greater prosperity for all may be desirable even when inequalities between different people increase. The identification of an ideally just society, even when it is possible, does not answer these practically important questions. Guidance for the pursuit of justice can remain in some chaos even if we try to follow as rigorously as we can the demands of the social contract approach, beginning with the search for ideally just institutions.

In contrast with social contract theorists, a number of other Enlightenment thinkers (beginning with Adam Smith, the Marquis de Condorcet, and Mary Wollstonecraft, and extending later to Karl Marx and John Stuart Mill, among others) took a variety of approaches that differed in many ways from each other, but shared a common interest in making comparisons between different ways in which people's lives may go, jointly influenced by the workings of institutions, people's actual behavior, their social interactions, and other factors that have a significant impact on what actually happens. The analytical (and rather mathematical) discipline of "social choice theory," which had its origin in the works of French mathematicians in the eighteenth century, in particular the Marquis de Condorcet, but also others like Jean-Charles de Borda, and which has been revived and reformulated in our times by Kenneth Arrow, belongs robustly to this second line of investigation.

I have to declare an interest here, since I have been very involved in the development and use of social choice theory. ${ }^{15}$ In my work on justice, I have tended to focus particularly on the exploration of the constructive possibilities of that approach (going beyond Kenneth Arrow's focus on generating impossibility results); and I have been involved over some decades in the derivation and elucidation of the demands of justice, with the help of the mathematical discipline of social choice theory, but supplemented by general (and largely nonmathematical) political and moral reasoning. ${ }^{16}$

Even though this way of reformulating the idea of justice is a departure from Rawls's justice as fairness, it can be broadly in line with what Rawls says about the relation between objectivity and public reasoning (without confining the reasoning involved to discussions within a sovereign state, ruling out global arguments). The domain of discourse can include alternative social states, the focus of attention can be the rankings-and partial orderings-of these states, and 
participants in public reasoning can include anyone who is willing to engage in reasoned arguments on alternative states and their merits. Ethical arguments would need to be complemented by economic reasoning, and interest in partial agreements would have to be clearly distinguished from an all-or-nothing search for perfectly just social arrangements.

In fact, arguments of this kind already take place in the world in various forms. What is needed is to make these attempts at public reasoning more extensive, more systematic, and much better informed, partly through expanding the vehicles of dissemination of information, strengthening the facilities for "fact-checking" and for the scrutiny of "fake news," and doing what we can to remove the barriers to public discussion. If there are bound to be difficulties in advancing the assessment of global justice through public reasoning, we should have at least the satisfaction of not being led into chaos by relying on misdirected engagements promoted by the social contract approach.

It is not hard to see that justice in the world demands many reforms and many new institutions and practices. In the field of global justice, there is no dearth of problems to consider and address. There are the long-lasting problems of global poverty, hunger, illiteracy, and persistent medical neglect. Epidemics rage over helpless people in different parts of the globe. Even in rich countries, the unemployed and the medically insecure can lead very deprived lives. There are also challenges of subduing terrorist violence, and of coping with global warming by looking for more efficient energy use as well as cheaper and more useable production of sustainable energy. There is also, I believe, the growing danger of nuclear accidents and nuclear terrorism as the world gets more and more crowded with nuclear power plants-the risks of which have been, I believe, hugely underestimated. All these subjects (and many others) are eminently suitable for public discussion and reasoned engagement across national borders: on how to increase security, reduce risks, expand human freedom, curtail inequality, and eliminate destitution.

Issues of cross-border relations influence people's lives everywhere in the world, since we no longer live in secluded little boxes. Our lives are globally interdependent, and what happens in Syria or Brazil or Rwanda or France can deeply influence the lives of people in a great many other countries as well. If the jointness of problems of justice is a global reality, interactive and informed reasoning is surely 
a global necessity. In an essay called "Of Justice"-written in 1771, in the very early days of economic globalization-David Hume wrote: "Suppose that several distinct societies maintain a kind of intercourse for mutual convenience and advantage, the boundaries of justice still grow larger, in proportion to the largeness of men's views, and the force of their mutual connexions." ${ }^{17}$

Boundaries of justice have not stopped growing since those early days of global interdependence.

\section{NOTES}

${ }^{1}$ John Rawls, A Theory of Justice (Cambridge, Mass.: Harvard University Press, 1971); also his Political Liberalism (New York: Columbia University Press, 1993).

2 Thomas Nagel, "The Problem of Global Justice," Philosophy and Public Affairs 33, no. 2 (2005).

${ }^{3}$ Ronald Dworkin, "What Is Equality?" Philosophy and Public Affairs 10 (1981), no. 3 (pp. 185-246) and no. 4 (pp. 283-345); and his Sovereign Virtue: The Theory and Practice of Equality (Cambridge, Mass.: Harvard University Press, 2000).

${ }^{4}$ Nagel, "The Problem of Global Justice," p. 115.

5 Thomas Hobbes, Leviathan (1651), ed. Richard Tuck (Cambridge: Cambridge University Press, 1991). Also, John Locke, Two Treatises of Government (1689), ed. Peter Laslett (Cambridge: Cambridge University Press, 1988); and Jean-Jacques Rousseau, The Social Contract (1762), ed. Maurice Cranston (Harmondsworth: Penguin, 1968).

${ }^{6}$ While discussing how justice can be effectively pursued when there is an "antecedent covenant"-a much broader notion than a devised social contract-Hobbes went on to point out that "if we could suppose a great Multitude of men to consent in the observation of Justice, and other Lawes of Nature, without a common Power to keep them all in awe; we might as well suppose all Man-kind to do the same; and then there neither would be nor need to be any Civill Government, or Common-wealth at all; because there would be Peace without subjection" (Leviathan, p. 118).

7 Richard Tuck, Hobbes (Oxford and New York: Oxford University Press, 1989).

8 A number of entries in the Encyclopedia of Global Justice, edited by Deen Chatterjee (Dordrecht: Springer, 2011), have addressed particular problems of ethics and economics related to global justice.

9 John Rawls, Political Liberalism (New York: Columbia University Press, 1993), p. 119.

${ }^{10}$ I have tried to say a bit more on this issue in the 2015 Annual Lecture to the Royal Institute of Philosophy: see "Reason and Justice: The Optimal and the Maximal," Philosophy 92, no. 1 (2016).

${ }^{11}$ Amartya Sen, The Idea of Justice (London: Allen Lane, and Cambridge, Mass.: Harvard University Press, 2009).

${ }^{12}$ See also Deen Chatterjee, "Reciprocity, Closed-Impartiality, and National Borders: Framing (and Extending) the Debate on Global Justice," Social Philosophy Today 27 (2011), pp. 199-215.

${ }^{13}$ The critically important role of allowing incomplete agreements is discussed in my essay, "Reason and Justice: The Optimal and the Maximal" (2016).

${ }^{14}$ Herbert Hart, "Rawls on Liberty and Its Priority," University of Chicago Law Review 40, no. 3 (1973). See also Rawls's discussion on this in Political Liberalism (1993), Lecture VIII.

${ }^{15}$ Amartya Sen, Collective Choice and Social Welfare (San Francisco: Holden-Day, 1970, and Amsterdam: North-Holland, 1979; expanded edition, London: Penguin, and Cambridge, Mass: Harvard University Press, 2017).

16 The expanded edition of Collective Choice and Social Welfare (2017) discusses a number of serious problems of injustice in the contemporary world.

17 David Hume, An Enquiry Concerning the Principles of Morals (1771, republished, La Salle: Open Court, 1966), p. 25. 